\title{
EL SENTIDO DEPORTIVO DE LA VIDA EN LA HERMENÉUTICA RACIOVITALISTA DE ORTEGA Y GASSET
}

\author{
JESÚS CONILL SANCHO \\ Universidad de Valencia $^{1}$
}

\begin{abstract}
RESUMEN: El trabajo pretende mostrar, en primer lugar, que el raciovitalismo de José Ortega y Gasset constituye una de las líneas posibles del proceso de transformación hermenéutica del pensamiento contemporáneo. La impronta nietzscheana de carácter hermenéutico en el desarrollo del pensamiento orteguiano se manifiesta en aspectos muy relevantes, como la importancia del cuerpo y la innovadora noción de vida, que son asuntos decisivos para comprender el deporte.

En segundo lugar, hay que aprovechar las ricas reflexiones de Ortega y Gasset sobre el deporte, que tienen un alcance muy relevante para la entera vida humana, a partir de la reivindicación de una noción de cuerpo viviente (Leib) y de una nueva noción de la vida. El deporte forma parte de un horizonte vital no reducido por la estrecha perspectiva utilitaria, sino que anuncia la forma superior de la existencia humana, la apertura a un sentido festival y creativo de la vida. Ésta exige una disciplina, que no se conforma con el mero cumplimiento correcto de unas normas, sino que incita a perfeccionarse indefinidamente. La cualidad de lo deportivo es la vitalidad creativa, una nueva forma de entender la vida. Porque desde esta nueva perspectiva vital, ya no sirve como modelo el homo oeconomicus, sino que el fenómeno vital entendido de modo deportivo es festival, alegre, creativo, agonal y olímpico, libérrimamente esforzado, fuente de energía con sentido. La vida es en principio creación, experimento creador, como en la concepción nietzscheana.
\end{abstract}

PALABRAS CLAVE: hermenéutica; deporte; Ortega y Gasset; Nietzsche; vida; cuerpo.

\section{The Sporting Sense of Life in Ortega y Gasset's Ratiovitalistic Hermeneutics}

ABSTRACT: This work aims to show, in the first place, that the ratiovitalism of Jose Ortega y Gasset is one of the possible lines of the hermeneutics transformation process of contemporary thinking. Nietzsche's hermeneutical mark on the development of Ortega's thinking is clear in some very relevant aspects, such as the importance of the body and the innovative notion of life, both of which are decisive issues to understand sport.

Secondly, an attempt is made to tap into the rich reflections of Ortega y Gasset on sport, which have a considerable impact on the entire human life, based on the claim of a notion of living body (Leib) and of a new notion of life. Sport forms part of a vital horizon that is not reduced by the narrow utilitarian perspective, but which announces the superior form of human existence, opening up to a festival and creative meaning of life. This requires a discipline that is not merely satisfied with correctly complying with some standards, but which encourages indefinite improvement. The attribute of sport is creative vitality, a new way of understanding life. Because, based on this new vital perspective, homo oeconomicus can no longer be used as a model, but rather, the vital phenomenon understood in a sporting manner is festival, joyful, creative, agonal and Olympic, freely vigorous, a meaningful source of energy. Life is, in principle, creation, a creative experiment, as in the Nietzschean conception.

KEY WORDS: hermeneutics; sport; Ortega y Gasset; Nietzsche; life; body.

1 Este estudio se inserta en el Proyecto de Investigación Científica y Desarrollo Tecnológico FFI2016-76753-C2-1-P, financiado por el Ministerio de Economía y Competitividad, y tiene su origen en «Ratiovitalistic hermeneutics and sport in the perspective of Ortega y Gasset», Sport, Ethics, and Philosophy, A. Edgar, E. Isidori y J. López-Frías (ed.), Sport and Hermeneutics, Routledge, 2016. 


\section{IMPRONTA NIETZSCHEANA DE LA HERMENÉUTICA RACIOVITALISTA DEL DEPORTE}

La transformación hermenéutica de la filosofía por parte del raciovitalismo de Ortega y Gasset constituye una contribución enriquecedora del panorama filosófico contemporáneo ${ }^{2}$, porque significa una superación del idealismo y del subjetivismo ${ }^{3}$, pero también del triunfante positivismo. Algunas posibles salidas a esta encrucijada histórica del pensamiento fueron el giro práctico de la filosofía (su presunta «realización», al estilo marxiano), las filosofías de la vida y de la historia (entendidas como cosmovisiones), la genealogía, la fenomenología, el pragmatismo y la hermenéutica. De todas ellas participa el pensamiento de Ortega y Gasset, ofreciendo una filosofía práctica, vital e histórica, que se caracterizará por un peculiar sentido hermenéutico. Aunque entre las diversas vías de hermeneutización del pensamiento contemporáneo la nietzscheana ha sido la decisiva en Ortega y Gasset, sobre todo para comprender el fenómeno del deporte.

Cuando se habla de hermenéutica se piensa habitualmente en la línea «oficial», que arranca de Schleiermacher y Dilthey, y tras Heidegger ha desarrollado Gadamer ${ }^{4}$, llegando hasta diversas formas de hermenéutica crítica ${ }^{5}$. Pero también en Ortega y Gasset encontramos varias líneas hermenéuticas, que se articulan en su filosofía del raciovitalismo histórico, y de entre ellas la impronta hermenéutica de Nietzsche ha marcado el pensamiento orteguiano en aspectos muy relevantes, como la importancia del cuerpo, la noción de vida y su valor, la fantasía, la etimología y las metáforas ${ }^{6}$, la noción de razón vital e histórica, es decir, una razón impura por el hecho de ser experiencial, y de modo especial la comprensión del deporte.

Una cuestión fundamental de la influencia nietzscheana fue su nueva noción de la vida. Es éste un asunto que proviene de Kant y Hegel, y que persiste a lo largo del siglo XIX y comienzos del XX. Ya Kant, en la Crítica del Juicio, otorga a esta noción un lugar crucial7; y el joven Hegel concedió la primacía a dicha noción, que más tarde se transforma en la omnímoda noción de «espíritu» ${ }^{8}$.

En la nueva idea de la vida van a integrarse elementos que parecían antitéticos, como el carácter orgánico y animal, por un lado, y el ideal cultural y ético, por otro, que, tanto en Nietzsche como en Ortega se resolverá, a mi

\footnotetext{
2 Apel, K.O., La transformación de la filosofía, Taurus, Madrid, 1985.

3 OrRinger, N. R., «Ortega, psicólogo y la superación de sus maestros», Azafea, 1 (1985), 185-236.

4 Vid. Gadamer, H.-G., «Hermeneutik», en Historisches Wörterbuch der Philosophie, J. Ritter (Hrsg.), Bd. 3, Schwabe \& Co., Basel/Stuttgart, 1974, 1061-1073.

5 Como, por ejemplo, Karl-Otto Apel, Jürgen Habermas, Paul Ricoeur, Charles Taylor, Gianni Vattimo, Jean Grondin, Mauricio Beuchot, Adela Cortina y Jesús Conill.

6 Vid., por ejemplo, Rivero, A., «José Ortega y Gasset: el deporte como metáfora», Revista internacional de ciencias del deporte, VII/23, 2011, 155-157.

7 Vid. Conill, J., Ética hermenéutica, Tecnos, Madrid, 2006.

8 Vid. Marcuse, H., Ontología de Hegel y teoría de la historicidad, Martínez Roca, Barcelona, 1972 (2 ed.).
} 
juicio, en una hermenéutica genealógica de la vida desde su facticidad. La compatibilidad entre la genealogía animal y la apertura ética se encuentra ya en el neokantismo de Lange, que es una de las fuentes más importantes del pensamiento científico y filosófico de Nietzsche ${ }^{9}$. En esta línea, no hay una contraposición entre las investigaciones sobre la evolución y el carácter perfectivo de la ética para el hombre. Esta concepción une la dimensión animal y el ideal ético, biología y ética, haciendo compatibles a Darwin y a Kant ${ }^{10}$. Lo cual no implica que Ortega esté de acuerdo con el darwinismo, como tampoco lo estuvo Nietzsche; antes bien, ambos criticaron la doctrina de la adaptación al medio y la lucha por la vida, por su carácter utilitarista, en favor de la fuerza creadora, del carácter deportivo, festival y lujoso de la vida, en el que coinciden, al menos desde Rolph, Nietzsche, Ortega, Unamuno y Scheler ${ }^{11}$.

Ortega se ha inspirado en el enfoque nietzscheano para pasar de la preponderancia de la razón lógica al sentido de la razón en el mundo de la vida. La hermenéutica genealógica nietzscheana llega hasta las fuerzas vitales, para lo cual se rige por «el hilo conductor del cuerpo», porque cuanto mejor conozcamos el cuerpo, más profundizaremos en la «experiencia vital»: «detrás de tus pensamientos y sentimientos (...) se encuentra un soberano poderoso, un sabio desconocido - llámase sí mismo (Selbst). En tu cuerpo habita, es tu cuerpo" ${ }^{12}$. Por esta vía, de inspiración nietzscheana, el raciovitalismo orteguiano rebasa el ámbito de la conciencia y del yo, proponiendo una «noción corporal del sujeto» ${ }^{13}$.

Nietzsche se encuentra en el trasfondo de la génesis de la razón vital. Pues Ortega recurre al «Dionysos» nietzscheano para expresar este sometimiento de la razón a la vitalidad, concluyendo su tesis fundamental: «La razón pura tiene que ceder su imperio a la razón vital» ${ }^{14}$. Ahora bien, el modo hermenéutico de acceder a la realidad viviente evita el biologismo y el irracionalismo, aunque manteniendo como clave interpretativa la nueva noción de vida.

En efecto, la noción orteguiana de vida no puede entenderse en sentido biologista, ni sirve para sustentar ningún irracionalismo, y está muy lejos de la utilitarista y hedonista. La vida no consiste radicalmente en adaptarse al medio, sino en adaptarse el medio para vivir. Porque la vida es en principio creación, experimento creador, como en la concepción nietzscheana. De ahí el sentido "deportivo» que encontramos en Ortega y que, por lo demás, es tan cercano al dionisíaco de Nietzsche. Una nueva concepción de la vida, que se ha

9 Vid. Conill, J., El poder de la mentira. Nietzsche y la política de la transvaloración, Tecnos, Madrid, 1997.

10 Ortega y Gasset, J., Obras Completas (= O.C.), Taurus, Madrid, 2004-2010, I, 202 y 387.

Vid. Morón, C., El sistema de Ortega y Gasset, Alcalá, Madrid, 1968, 172.

Nietzsche, F., Así hablo Zaratustra, Alianza, Madrid, 1984, 61.

Ortega y Gasset, J., O.C., «Las dos grandes metáforas» (1924), II, 512 y «Vitalidad, alma, espíritu» (1924), II, 566 ss.; «Sobre la expresión fenómeno cósmico» (1925), II, 680 ss.; Conill, J., El poder de la mentira, cap. IX.

14 Ortega y Gasset, J., O.C., «El tema de nuestro tiempo» (1923), III, 593. 
ido gestando durante todo el siglo XIX, en la que se descubre la unión de ética y biología en un contexto evolucionista, pues fue en los círculos kantianos y también en Nietzsche donde Ortega percibió la compatibilidad radical entre el evolucionismo y Kant ${ }^{15}$. Aunque, dentro del enfoque evolucionista, Nietzsche y Ortega defienden un sentido no darwiniano de vida, puesto que la vida no se entiende como «adaptación», sino como «poder creador» ${ }^{16}$, remitiendo Ortega explícitamente a la «interpretación» nietzscheana de la vida y elevando a Nietzsche a la categoría de "sumo vidente» y, por tanto, en clave hermenéutica, de sumo intérprete del «sentido» de la vida, de lo que es la vida «ascendente» y «lograda», del «valor de la vida» ${ }^{17}$. Por tanto, las bases para la transformación hermenéutica de la razón y su relación con la razón vital se encuentran ya en la vinculación de Ortega con Nietzsche ${ }^{18}$.

Otro aspecto de la transformación hermenéutica del pensamiento consiste en el recurso de Ortega a la «razón histórica» ${ }^{19}$. El carácter más auténtico del pensamiento no le viene de los esquemas lógicos, sino de su trasfondo vital e histórico. Esta supeditación de la razón a la vida y a la historia favorece una "genealogía de la cultura» y promueve que la cultura sea vital, "porque no hay cultura sin vida». "La cultura nace del fondo viviente del sujeto y es (...) vida sensu stricto, espontaneidad, "subjetividad"». Pero "la cultura sólo pervive mientras sigue recibiendo constante flujo vital de los sujetos. Cuando esta transfusión se interrumpe, y la cultura se aleja, no tarda en secarse y hieratizarse. (...) En las épocas de reforma como la nuestra, es preciso (...) fomentar la cultura emergente $-\mathrm{o}$, lo que es lo mismo, quedan en suspenso los imperativos culturales y cobran inminencia los vitales» ${ }^{20}$. Por eso, «el tema de nuestro tiempo consiste en someter la razón a la vitalidad» y presentar las exigencias vitales a la cultura («ante el juez infalible Dionysos»); se trata de rebasar la razón formal en favor de una razón vital y así descubrir los «valores inmanentes a la vida», de los que forma parte la vitalidad deportiva.

Ortega recurre en este contexto a Nietzsche para reforzar su idea de la necesidad de sentir y vivir la vida plenamente en cada instante, haciendo que «el ideal fluya por la jornada entera» y sea una «espuela» con "poder de arrebatarnos y hacernos felices» ${ }^{21}$. A lo que se está aludiendo es al nivel subterráneo del sentimiento, de la pasión y del poder (Macht) como «poderío» vital. Porque el

15 Ortega y Gasset, J., O.C., I, 202 Y 387.

16 Ortega y Gasset, J., O.C., VII, 314-316.

17 Ortega y Gasset, J., O.C., III, 601-605 («valores vitales»).

18 Cfr. Regalado, A., El laberinto de la razón: Ortega y Heidegger, Alianza, Madrid, 1990; Conill, J., El poder de la mentira. Nietzsche y la política de la transvaloración, Tecnos, Madrid, Parte III; Zamora, J., Ortega y Gasset, Plaza y Janés, Barcelona, 2002.

19 Ortega y Gasset, J., O.C., «El hombre y la gente», X, 276; «La razón histórica [Curso de 1940]», IX, 477-558; «La razón histórica» [Curso de 1944], IX, 625-700.

20 Ortega y Gasset, J., O.C., «El tema de nuestro tiempo» (1923), III, 587-8.

21 Ortega y Gasset, J., O.C., «Ideas sobre Pío Baroja», II, 230. Para la comprensión de lo deportivo como ideal, vid. Ilundáin-AgurRuza, J., «José Ortega y Gasset: Exuberant Steed», Sport, Ethics and Philosophy 8 (3), 2014, 285-314 (p. 289). 
pensamiento no nace de símismo, sino de una «potencia preintelectual». Con este apoyo nietzscheano se avanza en la dirección de superar el «intelectualismo», que toma la parte por el todo de la existencia, dejando fuera el potencial de la «vitalidad ascendente», que proviene de los estados previos a la razón y que en realidad forman parte de un nivel protorracional. La transformación hermenéutica de la razón requiere su vitalización e historización. La razón histórica completa las aportaciones de la razón vital y corporal (Vernunft im Leben y Vernunft im Leibe) en una hermenéutica raciovitalista, en la que el sentido y la ejecutividad se presentan como los aspectos más radicales para comprender el trasfondo vital — la facticidad ejecutiva- de los fenómenos humanos.

Este análisis hermenéutico de la experiencia fáctica de la vida parte del polifacético saber vital, del sabor miriádico de la vida (Lebensgefühl); es decir, arranca de la facticidad de la vida humana, cuyo dinamismo experiencial es originariamente interpretador y estimador (evaluador y preferidor). Mediante este acceso experiencial a la facticidad vital e histórica, Ortega busca una nueva forma hermenéutica de abordar la realidad humana en consonancia con la razón vital, histórica y narrativa ${ }^{22}$.

Sin embargo, hay quienes han entendido que esta hermenéutica raciovitalista asume un cierto giro pragmático, por el que todo concepto es una respuesta vital y constituye una acción; es ésta una perspectiva que ha sido desarrollada en sentido pragmatista por John Graham ${ }^{23}$ y destacada por Jesús Ilundáin-Agurruza en relación con la filosofía deportiva: el análisis existencial orteguiano entiende la vida como un asunto deportivo ${ }^{24}$. «Ortega construye su filosofía de la vida basándose en el deporte» y «usa el deporte para revelar la estructura de la vida y cómo la experimentamos» ${ }^{25}$.

Por su parte, David Inglis sugiere que el análisis filosófico del deporte que ofrece de modo pionero Ortega y Gasset se sitúa en el ámbito fenomenológico, estableciendo una ilustrativa relación de semejanza entre los análisis filosóficos del deporte de Ortega y de Bernard Suits ${ }^{26}$, sobre todo por lo que respecta a determinadas correspondencias entre las actividades deportivas y varios rasgos significativos de la vida humana, destacando que los deportes son parte de la cultura y símbolo de la condición humana, manifestación de la humanidad y de su situación existencial (vital). No obstante, Inglis destaca una diferencia entre ambos: Suits se orienta más al análisis de las reglas de los deportes (los aspectos formales), destacando las «reglas constituyentes» del juego [game] y sus principales

22 Ortega y Gasset, J., O.C., «Historia como sistema» (1941), VI, p. 71; «La razón histórica [Curso de 1940]», IX, 552-558.

23 Graham, J. T., A pragmatist philosophy of life in Ortega y Gasset, University of Missouri Press, Columbia, SC, 1994.

24 Ilundáin-Agurruza, J., «José Ortega y Gasset: Exuberant Steed», 290.

25 Ibid., 288.

26 Inglis, D., «Meditations on sport: On the trail of Ortega y Gasset's philosophy of sportive existence», Journal of the Philosophy of Sport, 31 (1), 2004, 84-85. 
elementos (meta, medios y reglas) ${ }^{27}$; mientras que Ortega centra su análisis en lo vital y existencial, en la perspectiva más cultural de Johan Huizinga ${ }^{28}$.

Sin prescindir de las aportaciones fenomenológicas y pragmatistas, considero que la comprensión del deporte queda mejor situada en un marco hermenéutico como el que han ido elaborando Emanuele Isidori y Javier López Frías. El deporte es una característica del hombre a partir de su corporeidad, que expresa su ansia de constante superación y cuya raíz se encuentra en la condición humana ${ }^{29}$.

\section{EtIMOlogía Y SENTIDO FELICITARIO DEL DEPORTE}

La etimología, según Ortega, nos permite descubrir situaciones «vividas», en las que queda conservada su «actualidad» vital; «etimología» es un nombre de la «razón histórica» ${ }^{30}$ y, por tanto, cabe hablar de una hermenéutica etimológica, en la que empezamos a comprender el sentido de lo que el hombre hace y de lo que es. Razón histórica y vital van juntas ${ }^{31}$ en su pretensión de desvelar la estructura de la vida humana.

En concreto, Ortega y Gasset remite a la etimología del término «deporte»: procede de la lengua gremial de los marineros mediterráneos, que a su vida de trabajo oponían su vida en el puerto, el «estar de portu», visitando las tabernas, conversando con gentes de otras culturas y participando en los juegos deportivos. Al parecer, en la cultura trovadoresca de Provenza se encuentran las palabras «deports e solatz», donde «deport» es el juego de conversación y poesía, mientras que «solaces» representa los ejercicios corporales, pero en conjunto dichos términos se refieren a lo "felicitario» ${ }^{32}$.

Esta contraposición entre la vertiente «trabajosa» de la vida y la «felicitaria»proviene del fondo de la condición humana, dado que dentro del

27 SuIts, B., "Construction of a definition», from The Grasshopper, in The Ethics of Sports. A Reader, edited by Mike MacNamee, Routledge, London and New York, 2005, 17-28.

28 INGLIS, D., "Meditations on sport: On the trail of Ortega y Gasset's philosophy of sportive existence», 95, nota 4. Vid. Huizinga, J., Homo ludens: vom Urspung der Kultur im Spiel, Rowohlt, Hamburg, 1958.

${ }_{29}$ Isidori, E., ReID, L., Filosofia dello sport. Milano: Mondadori, 2011; López Frías, J., 2014. La filosofia del deporte actual. Paradigmas y corrientes principales, Quapeg, Rome, 2014.

30 Ortega y Gasset, J., O.C., «El hombre y la gente [Curso de 1949-1950]», X, 276.

31 Vid. Zamora, J., Ortega y Gasset, 394 y 590-591, nota 31.

32 Ortega y Gasset, J., O.C., «Prólogo a Veinte años de caza mayor, del Conde de Yebes» (1943), O.C., VI, 277-278, nota. También en Nietzsche se constata una relación de su «gaya ciencia» o "gay saber» con la cultura provenzal: vid. CAMPIONI, G., «"Gaya ciencia” y "gay saber" en la filosofía de Nietzsche», en J. Conill-Sancho y D. Sánchez-Meca, Guía Comares de Nietzsche, Comares, Granada, 2014, 71-91. Campioni nos advierte que en el fragmento 11 [337], de primavera-otoño de 1881, en los «Lieder der Freude» [cantos de alegría], hay un «error de desciframiento»: «Sontas» está en lugar de «Soulas» (Solatz, Solacium), que en el lenguaje trovadoresco prevalece el sentido de alegría (en italiano: solazzo, diversión). 
hombre biológico y utilitario hay «otro hombre lujoso y deportivo» ${ }^{33}$, que constituye una «raíz» o "dimensión» del ser humano imposible de explicar a partir del «principio utilitario». De modo que ya en este contexto lo más destacable es el impulso poético de la cultura provenzal, creadora e inventiva.

De un modo significativo Ortega añade que en alguna crónica provenzal «deportar»se refiere a «cazar» ${ }^{34}$ y precisamente explicará el sentido felicitario de los deportes tomando como ejemplo la caza ${ }^{35}$, que es una ocupación felicitaria, pero esforzada. Las «ocupaciones felices» no son meros placeres, sino ocupaciones liberadas, «esfuerzos», como los «verdaderos deportes». La distinción entre el trabajo y el deporte no radica en que haya, o no, esfuerzo y fatiga, sino en que «el deporte es un esfuerzo hecho libérrimamente, por pura complacencia en él, mientras el trabajo es un esfuerzo hecho a la fuerza en vista de su rendimiento ${ }^{36}$. El deporte es un esfuerzo que en oposición al trabajo no nos es impuesto, ni es utilitario, sino espontáneo, lujoso, que hacemos por el gusto de hacerlo, que se complace en sí mismo ${ }^{37}$. El trabajo es «el esfuerzo que la necesidad impone y la utilidad regula»; en cambio, el deporte nace "como espontánea eflorescencia del esfuerzo superfluo y desinteresado en que toda naturaleza pletórica suele buscar esparcimiento ${ }^{38}$.

Inglis valora el estudio orteguiano de la caza como actividad deportiva, para explicar la índole del ser humano a partir de su cualidad deportiva; porque la esencia de la caza no está en la utilidad ni en el placer, sino en la relación entre cazador y presa, en la que destaca tres elementos: el hecho natural de la «jerarquía zoológica», la desigualdad de capacidades y las intenciones del cazador, el afán por una ocupación liberada y felicitaria, que se hace por sí misma ${ }^{39}$.

Ciertamente, sin esfuerzo y disciplina es «imposible hacer nada importante en el mundo». Pero ese esfuerzo surge de una "disciplina interior ${ }^{40}$, de una energía que se adquiere en los «ejercicios deportivos». Ortega anuncia una próxima publicación con el título "Marta y María, o Trabajo y deporte», en la que quiere mostrar la prioridad del «deportismo» en la vida ${ }^{41}$. Esta «cualidad deportiva» es «algo que se añade lujosamente a lo que es necesario e

33 Ortega y Gasset, J., O.C., "¿Qué es la ciencia, qué es la filosofía?» (1928), VIII, 138.

34 Ortega y Gasset, J., O.C., «Prólogo a Veinte años de caza mayor, del Conde de Yebes» (1943), VI, 278, nota.

35 Vid. Ortega y Gasset, J., O.C., «Prólogo a Veinte años de caza mayor, del Conde de Yebes»(1943), VI, 269-333.

36 Ortega y Gasset, J., O.C., «Prólogo a Veinte años de caza mayor, del Conde de Yebes» (1943), VI, 277.

37 Ortega y Gasset, J., O.C., «¿Qué es filosofía?»(1929), VIII, 294.

38 Ortega y Gasset, J., O.C., «El Quijote en la escuela» (1920), II, 427.

39 Inglis, D., «Meditations on sport: On the trail of Ortega y Gasset's philosophy of sportive existence», 88-90.

40 Ortega y Gasset, J., O.C., «Carta a un joven argentino que estudia filosofía» (1924), II, 467-471.

41 Ibid., 470. 
imprescindible», al «mínimo exigible» de lo correcto, porque lo que significa es una exigencia de «perfección», que nos «la ponemos (...) por libérrimo acto de albedrío»y «merced a que nos complace su ejercicio» ${ }^{42}$.

En el lenguaje de los deportistas, lo importante es «estar en forma», porque entonces cambia radicalmente lo que uno es «capaz de hacer». «Pero la forma tiene que ser conquistada» ${ }^{43}$ y para lograrla se requiere entrenamiento, "no abandonarse nunca en nada ${ }^{44}$. Para estar en forma hay que disciplinarse, sabiendo lo que uno se propone, prepararse y «formarse» como es debido venciendo la inercia.

\section{DiFERENCIA ENTRE DEPORTE Y JUEGO}

La diferencia entre ambos es que el deporte «incluye un riesgo» ${ }^{45}$. El deportista no rehúye el peligro, sino que incluso lo busca, y con ello muestra otra manera de valorar la vida y la muerte. A diferencia del sentir propio del «espíritu industrial» y «del ánimo burgués», que «quiere a toda costa vivir», el deportista prefiere «la moral de la vida alta», una «moral de más quilates», según la cual entiende que "posee la vida para exponerla con sentido». Por eso la nueva moral del deportismo, el espíritu deportivo, invita a «organizar el peligro», a que "seamos poetas de la existencia» ${ }^{46}$.

Aunque se suele considerar el deporte como el juego del adulto, Ortega lo considera un error, procedente del habitual concepto de juego infantil y sugiere que «el juego es una idea formada desde el punto de vista del adulto que trabaja ${ }^{47}$. La idea de juego se contrapone a la del trabajo y a la seriedad de la vida. Para los niños «el trabajo no existe», «vivir es jugar» ${ }^{48}$. De ahí que el juego no nos dé una idea clara del deporte, pues éste empieza donde comienza el esfuerzo, que es donde el juego acaba. Por ejemplo, el alpinismo, la caza, el fútbol, la regata, etc., son ejemplos de faenas duras, que, como tantos otros deportes, suelen ser peligrosos ${ }^{49}$.

Por tanto, no hay que confundir el deporte con el juego. Según Ortega, el juego es un nombre que propiamente sólo es aplicable a la actividad infantil. «El niño juega siempre». «En el adulto el juego no es esfuerzo sino descanso y diversión. Se detiene donde lo penoso comienza que es precisamente donde empieza el deporte. Le faltan todos los atributos de éste: entrenamiento, disciplina,

\footnotetext{
42 Ibid. «No ser hombre ejemplar» (1924), II, 475-479.

43 Ortega y Gasset, J., O.C., «Temple para la reforma», IV, 1039.

44 Ibid. IV, 1039.

45 Ibid., «Notas del vago estío» (1925), II, 546-549.

46 Ibid., 549.

47 Ortega y Gasset, J., O.C., «[Sobre el buen dolor]» (1920), VII, 758-760.

48 Es inevitable remitirse a Nietzsche y a la figura (metáfora) del niño que juega (cfr. Asi habló Zaratustra).

49 ORtega y Gasset, J., O.C., «[El sentido deportivo de la vitalidad]» (1924), VII, 833-834.
} 
riesgo - en suma, seriedad, gravedad». Los mejores hombres «han consumido sus vidas en puro frenesí deportivo», "han buscado y querido el peligro y el dolor» con "delirio festival», eludiendo la comodidad. Por ejemplo, las clases superiores en todo tiempo han hecho del deporte su «esencial ocupación»: su vida era una "fiesta», pero una fiesta peligrosa, que «ha fecundado las cosas mayores de la historia». Ortega recuerda las figuras de Marta y María, para resaltar el superior valor de la "generosa superfluidad del entusiasmo» y, desde esa interpretación jerarquizada de las actividades de la vida, en vez de definir al ser humano por sus momentos inferiores, lo define por su culminación, comprendiéndolo como «aquél para quien lo superfluo es lo más necesario ${ }^{50}$.

\section{ORigen DEPortivo de la cultura y del Estado}

Ortega llega a afirmar que «la cultura no es hija del trabajo, sino del deporte $»^{51}$. De entrada suena a «exageración $»^{52}$ y seguramente habría que decir que es hija de múltiples factores, al menos de las dos clases de actividades, la productiva y la deportiva, aun cuando haya una diferente valoración y, por tanto, una jerarquía vital entre ellas. Esta jerarquía vital es la que le sirve a Ortega para interpretar el origen de la organización social, que atribuye al carácter «sociable» y «hazañoso» de los jóvenes en las hordas primitivas, que necesitaban «acometer empresas» y cuyo «apetito de imaginación» les llevó a «robar las mozas de hordas lejanas», lo cual condujo a la guerra entre hordas y a una cierta organización social en cada una, basada en la disciplina y la autoridad de un jefe, que debía fomentar la unidad y la preocupación por los problemas comunes. En esta vida en común se cultivaron destrezas vitales mediante «entrenamiento»y, según Ortega, fue en esta «asociación política originaria» donde se ejercitó «el primer ascetismo», es decir, un «ejercicio de entrenamiento», convertido en "régimen de vida del atleta» ${ }^{53}$.

Como señala David Inglis, al margen de la validez empírica de la narración histórica que ofrece Ortega del origen deportivo de las instituciones sociales y políticas, lo más valioso es su visión de los aspectos «deportivos» de la existencia humana, en la medida que ayudan a comprender el fenómeno humano a partir del «poder creativo inherente a la actividad deportiva ${ }^{54}$. Pues la conclusión que saca Ortega de su narración de los orígenes de la primitiva organización social es que la primera sociedad humana es la «asociación de jóvenes para robar mujeres extrañas al grupo consanguíneo»; por consiguiente, «todo lo contrario

$50 \quad$ Ibid., 834.

51 Ibid., «El Quijote en la escuela» (1920), II, 427.

52 Vid. Lenk, H., «Tasks of the Philosophy of Sport: Between Publicity and Anthropology», Journal of the Philosophy of Sport, 9: 1, 1982, 94-106, 104.

53 Ortega y Gasset, J., O.C., «El origen deportivo del Estado» (1924), II, 714.

54 InGLIS, D., «Meditations on sport: On the trail of Ortega y Gasset's philosophy of sportive existence», 87. 
que una reacción a necesidades impuestas». De ahí que Ortega defienda «el origen deportivo y festival del Estado» ${ }^{55}$ y sitúe «la génesis histórica e irracional del Estado» en una amalgama de factores entre los que destaca «la gracia y no la utilidad» ${ }^{56}$. También David Inglis alude a estas «razones irracionales» como parte del principio clave de la vida, a una sobreabundancia fluyente de energías, al vigor vital, más allá de las razones utilitarias, en el origen de las instituciones sociales y políticas.

Así pues, en el origen del Estado se encuentra la "potencia deportiva», un ejemplo de «fecundidad creadora» y entre los "prototipos de la vitalidad primaria» que están en el inicio del "gran proceso político» menciona Ortega al «deportista $»^{57}$, su capacidad creadora de «posibilidades insospechadas $»^{58}$. Sin embargo, como las valoraciones dominantes en la vida humana han sido la utilidad y la justicia (contractual), hemos vivido sometidos al "predominio de dos tipos humanos»: el "homo oeconomicus y el abogado». Lo que Ortega señala es que «esos valores ni son los únicos ni son los superiores»y, por tanto, que «el mundo es más rico en calidades estimables», entre las que hay que «decidirse y preferir». La moral consiste en un «sistema de preferencias», somos vitalmente preferidores ${ }^{59}$, capaces de preferir otro modo de vida: por ejemplo, la de un nuevo tipo de hombre, para quien la vida tendría un sentido deportivo y festivo ${ }^{60}$. Esta diferencia entre dos tipos de hombre constituye la base de dos tipos de sensibilidad y de moral: la «moral del negocio» y la "moral del ocio o deporte»; la primera está basada en la prudencia calculadora ${ }^{61}$, y la segunda está orientada por una «inspiración agonal y olímpica» ${ }^{62}$ que es "creadora».

Ortega detecta que esta vitalidad creadora de inspiración deportiva ha promovido la unidad cultural desde antiguo y se ha extendido haciéndose ubicua en la época actual. Los deportistas acuden a concursos universales en los más remotos lugares, ensanchando el horizonte «hacia perspectivas planetarias»: «Esa unidad deportiva del globo terráqueo es la expresión primogénita de una futura unidad total». Porque «no fue la política ni fue la economía quien produjo las primeras unificaciones de los grupos humanos distantes o dispares, sino la fiesta deportiva» ${ }^{63}$. Ortega alude a los «juegos olímpico y délficos» en la antigua Grecia como un ejemplo de posible unificación cultural, a pesar de la

55 ORTEga y GasSET, J., O.C., «El origen deportivo del Estado» (1924), II, 714 y 719.

56 Inglis, D., "Meditations on Sport: On the Trail of Ortega y Gasset's Philosophy of Sportive Existence», Journal of the Philosophy of Sport, 31: 1, 2004, 78-96, 87.

57 Ortega y Gasset, J., O.C., «El origen deportivo del Estado» (1924), II, 715.

58 ORtega y Gasset, J., O.C. «El origen del Estado» II (1924/1925), III, 777-782.

59 Ibid., 778.

60 Ibid., 811

61 Ibid., 778. Ortega remite a la moral utilitaria de Bentham, figura del burgués moderno.

62 Ibid., 778. Ortega remite a la Ética de Aristóteles, a la metáfora de la búsqueda de «blanco» por parte del arquero, es decir, a la búsqueda y elección de la meta o el fin de nuestra vida. Para la pervivencia en Nietzsche del sentido del agón, vid. Tuncel, Y., Agon in Nietzsche, Marquette UP, Milwaukee, Wisconsin, 2013.

63 Ortega y Gasset, J., O.C., «Charla, nada más», IV, 77. 
imposibilidad de unirse de otra manera: «el máximum de unidad» se logró de esa forma y sólo así «nació la idea de la Hélade, de la cultura unitaria», que luego se extendió por Oriente y Occidente.

\section{Don QuiJOTE, «GRAN DEPORTISTA».}

Lo que la vitalidad deportiva pone en marcha es una nueva interpretación de la vida, un nuevo sentido de la vida ${ }^{64}$. Siempre contamos con algún «preconcepto» acerca de qué sea la vida, incluso en las ciencias biológicas de carácter experimental. No nos movemos entre hechos, sino que, remitiendo a Goethe, "todo hecho es ya teoría», es decir, una interpretación. Y Ortega añade: "Antes del hecho y después del hecho» funciona un horizonte, en el que los datos fenoménicos son interpretados mediante «perfiles» y «fisonomías significativas». Lo mismo ocurre con el fenómeno de la vida ${ }^{65}$.

En los últimos tiempos, la vida se ha entendido como «un conjunto de procesos útiles». Industriales, políticos y economistas han visto «en todo fenómeno orgánico un sentido de utilidad». Y la influencia del darwinismo ha impuesto la visión de que la vida es un fenómeno de lucha por la existencia y de adaptación al medio; pero, según Ortega, esta «interpretación de la vida» ha quedado superada, ya que desde una visión biológica «sólo descubre el sentido utilitario de la vida» ${ }^{66}$. Pero vivir no se reduce a "satisfacer necesidades», sino que es "acción espontánea», ni la vitalidad humana puede explicarse íntegramente sometida al «principio de la adaptación utilitaria». Sería un error de horizonte y de perspectiva ${ }^{67}$.

Por eso Ortega propone otra interpretación de la vida, mostrando que «la actividad adaptativa o utilista es siempre una manifestación secundaria de la vida que supone una actividad previa puramente lujosa, superflua, espontánea, no forzada, de cuyos actos va siendo seleccionado, mecanizado, aquel repertorio de movimientos ventajoso». Por tanto, no es la utilidad «el principio de la vida», sino que la «vida útil» es consecuencia de la «vida verdaderamente originaria», que consiste en «abundancia, generosa y ágil expansión, libérrima prodigalidad ${ }^{68}$. «La adaptación supone siempre una creación previa», la propia de una vida primaria, que es «inútil», pero que constituye el «poder» inicial de la vida. Más allá de las urgencias vitales, Ortega descubre el «origen poético, metafórico» de los objetos e instrumentos (por ejemplo, del arco y la flecha, del traje, del dinero, del cheque primigenio). Así se desvela otra manera de sentir la vida e interpretarla de modo no utilitario, porque «no fue la utilidad» el origen

\footnotetext{
64 Ortega y Gasset, J., O.C., «El sentido deportivo de la vitalidad» (1924), VII, 818-834.

65 Ibid., 822.

66 Ibid., 823 y 827.

67 Ibid., 825 .

68 Ibid., 826.
} 
de muchas de las «grandes adquisiciones» que llenan la vida humana, sino que se revelan como «creaciones de la superfluidad, motivadas por emociones transcendentes o cuando menos de lujo vital» ${ }^{69}$. Esta interpretación orteguiana de la vida como dinamismo creador establece una jerarquía vital y descubre que en todo origen «está la gracia y no la justicia o la necesidad» ${ }^{70}$. Pues incluso en la actividad utilitaria por excelencia, la economía, «interviene creadoramente ese otro poder superfluo de gracia, lujo y transcendencia».

Aunque toda vida es «esfuerzo y energía», hay dos formas de esfuerzo vital: 1) la reactiva, en la que el esfuerzo útil es el trabajo; 2) la creativa, en la que el esfuerzo se realiza por «íntimo impulso», de modo libérrimo e innecesario, y que tiene «carácter deportivo». En consecuencia, hay «dos formas esenciales de la actividad vital»: trabajo y deporte. El trabajo es mera respuesta a una exigencia imperiosa, donde "lo decisivo es el resultado útil»; en cambio, en el deporte, «el resultado no es lo importante sino la calidad misma del esfuerzo». Lo que vale en el deporte, vale "por sí mismo». Por eso, Ortega llega a calificar a Don Quijote de "gran deportista», como refleja su famoso aserto: "podrán los encantadores quitarme la ventura — pero el esfuerzo y el ánimo es imposible» ${ }^{71}$.

En efecto, «todo lo que posee un valor superior ha sido fruto y emanación de esfuerzos deportivos y superfluos», de la actividad primaria de la vida ${ }^{72}$, que es creación. De ahí que Ortega caracterice las actividades creativas e inventivas como formas de la «vitalidad deportiva» y remita en ocasiones a Platón para recordar que llamaba a la filosofía "ciencia de los hombres libres», «ciencia de los aristócratas» $\mathrm{y}$ «ciencia de los deportistas» ${ }^{73}$, porque el libre (eleútheros) en Grecia no admitía el trabajo como ocupación sino sólo el agón, el certamen deportivo ${ }^{74}$.

En suma, el deporte le sirve a Ortega para comprender el fenómeno de la vida desde su raíz fruitiva, porque «en la raíz de la Vida — es decir, en el estrato más básico y profundo del fenómeno Vida - hay junto a la Nada y la "angustia" una in-finita alegría deportiva» ${ }^{75}$. La vida es unidad de esas dos dimensiones: muerte y constante voluntad de existir, peligro viviente y jocundo desafío al peligro, «desesperación» y fiesta, en suma, «angustia» y «deporte» ${ }^{76}$. Por eso, Ortega contrapuso a la presunta exclusividad del «sentido trágico de la vida»

69 Ibid., 828

70 Ibid., 831. Vid. Cortina, A., Alianza y contrato. Política, Ética y Religión, Trotta, Madrid, 2001 .

${ }^{71}$ Ibid., p. 832. Vid. Ilundáin-AgurruZA, J., «José Ortega y Gasset: Exuberant Steed», Sport, Ethics and Philosophy, 8: 3, 2014, 285-314, 298.

72 Ortega remite al término «sports» para referirse a las mutaciones súbitas como actividad primaria de la vida, a diferencia de la adaptación utilitaria (ORTEGA y GASSET, J., O.C., VII, 833).

73 Ortega y Gasset, J., O.C., “¿Qué pasa en el mundo?» (1933), IX, 486.

74 Vid. Tuncel, Y., Agon in Nietzsche, Marquette University Press, Milwaukee, Wisconsin, 2013; Isidori, E. y ReID, H. L., Filosofia dello sport, B. Mondadori, Milan, 2011.

75 Ortega y Gasset, J., O.C., «La idea de principio en Leibniz»(1947), IX, 1140.

76 Ibid., 1140. 
(al estilo de Unamuno) un «sentido deportivo y festival» de la existencia. No obstante, aunque resulte paradójico, Ortega recuerda que al hombre «le gusta pasarlo mal», pero añade: "esto es la definición del deporte. El deporte es un esfuerzo muy rudo, a veces mortal, que se busca porque sí». Y en este contexto remite a la interpretación de Nietzsche y su sentido trágico-agonal de la vida: «¿Eso es la Vida? ¡Bueno, venga otra vez!». «La Vida es sentirse morir y gritar a la vez: da capo!» ${ }^{77}$.

\section{EL DEPORTE COMO FORMA SUPERIOR DE VIDA}

El deporte es «la forma superior de la existencia humana». Con un sentido bastante optimista, Ortega cree en este escrito de 1920 que la marcha de la sociedad obliga a una «reforma radical» de la mentalidad y anuncia «un viraje de la historia hacia un sentido deportivo y festival de la vida» ${ }^{78}$. Confía en que pueda cambiar el «tipo de hombre»: dependerá de si siguen imperando las ideas y los sentimientos del hombre «utilitario», es decir, de si el "poder social» está en manos del «homo oeconomicus» o si se hace predominante "otro tipo humano antieconómico, inutilitario», «vitalmente lujoso», «para quien vivir no es ganar sino (...) regalar». Lo cual supone que cambie el tipo humano que dirige la vida europea: que se pase de la preponderancia de los «financieros, abogados y periodistas» a un sentido más noble de la vida, «deportivo y festival».

Lo decisivo es la idea que tengamos de la vida. «En el siglo XIX (...) se fraguó una interpretación utilitaria del fenómeno vital», que «puede aún considerarse como el tópico vigente» ${ }^{79}$. La vida se presenta como un «fenómeno de utilidad y adaptación», una forma de vida "secundaria», «menguante», síntoma de debilidad $^{80}$. Pero, según Ortega, la nueva biología y la investigación histórica «invalidan» el «mito» utilitario y proponen otra idea de la vida, según la cual «la actividad original y primera es siempre espontánea, lujosa, de intención superflua, es libre expansión de una energía preexistente». Por tanto, no es un «tropismo» (movimiento forzado), sino «liberal ocurrencia», «imprevisible apetito», una «vida pujante» ${ }^{81}$.

Por consiguiente, según Ortega, hay dos formas de actividad vital: una originaria, creadora, vital por excelencia, espontánea y desinteresada; y otra que es utilitaria. Pero «la utilidad no crea, o inventa, simplemente aprovecha y estabiliza lo que sin ella fue creado». Esta diferenciación entre formas de actividad, que se da ya en los «fenómenos orgánicos», la aplica Ortega también a las «acciones», distinguiendo dos clases de esfuerzo vital: el «esfuerzo

77 Ibid., 1142.

78 Ortega y Gasset, J., O.C., «El Quijote en la escuela» (1920), II, 427.

79 Ortega y Gasset, J., O.C., «El origen deportivo del Estado» (1924), II, 705-719.

80 Ibid., 706-707.

81 Ibid., 707. 
obligado» para satisfacer una necesidad: el trabajo; y el «superfluo», el que hacemos «por la simple delectación de hacerlo»: el deporte.

Ortega no sólo establece una distinción entre el trabajo y el deporte, sino que propone una transmutación de la jerarquía axiológica entre ambas actividades, considerando la «actividad deportiva como la primaria y creadora, como la más elevada, seria e importante en la vida». Pues «vida propiamente hablando es sólo la de cariz deportivo», siendo la actividad laboriosa mera «mecanización» $\mathrm{y}$ «funcionamiento» ${ }^{82}$. Por tanto, «en todo proceso vital, lo primario (...) es una energía de sentido superfluo y libérrimo, lo mismo en la vida corporal que en la vida histórica» ${ }^{83}$. La vida consiste en invención y selección: "fue primero una pródiga invención de posibilidades y luego una selección entre ellas que se fijan y como solidifican en hábitos utilitarios». La vida de cada cual consiste en «la selección que las circunstancias afectivas han ido ejecutando entre sus posibilidades personales». La invención de abundantes posibilidades es síntoma de vida pujante, pero de entre ellas se produce una selección, que cuando se atiene a «lo estrictamente necesario» en el sentido utilitarista refleja un síntoma de debilidad y vida menguante.

En suma, «la vida es cuestión de pitos. Lo más necesario es lo superfluo». No basta con responder a la necesidad; si «la vida ha triunfado sobre el planeta» no se debe a que se atiene a lo estrictamente necesario, sino a su capacidad de ofrecer «exuberantes posibilidades». Y por eso Ortega destaca la palabra «incitación», por su peculiar «sabor de vida», ya que «sólo en biología tiene este vocablo sentido». En física una cosa no es incitación para otra, sino «causa». A diferencia del ejemplo del choque entre las bolas de billar, en el que «el efecto es en física igual a la causa», "cuando el aguijón de la espuela roza apenas el ijar del caballo pura sangre éste da una corveta magnífica, generosamente desproporcionada con el impulso de la espuela. La espuela no es causa, sino incitación ${ }^{84}$. La incitación produce una exuberancia vital, vida pujante, a partir de una vitalidad que no consiste en mera inercia. Las diversas «incitaciones punzantes» de la vida constituyen un «tesoro de vitalidad», más allá de la superficial inercia ${ }^{85}$.

Lo contrario de la inercia es la creación, que en «nuestro tiempo» ha impulsado el redescubrimiento del cuerpo, de cuya reivindicación «han venido los llamados deportes». En este contexto lo decisivo para la configuración del modo superior de vida será el ethos deportivo y su carácter «aristocrático» ${ }^{86}$. Porque lo más profundo de una persona no son sus opiniones ni sus ideas, sino «su carácter», sus sentimientos y «temperamento íntimo», que consiste en una «estructura de simpatías y antipatías nativas, de preferencias y posposiciones, de estimaciones y repulsiones». Pues, más allá de las ideas «operan ocultas

$82 \quad$ Ibid., 707.

83 Ibid., 708.

84 Ibid., 709.

85 Ibid., 709-710.

86 Ortega y Gasset, J., O.C., «[Militares y clases mercantiles]» (1920), VII, 754-757. 
nuestras personales valoraciones». Nuestra actividad primaria, según Ortega, es una "función estimativa»; "ella es la raíz de la persona y de ella depende la función intelectiva y volitiva y cuantas pueda distinguir la psicología en nuestra vida mental». El nombre que le da a ese "carácter estimativo», siguiendo la tradición del pensamiento griego, es «ethos». En una sociedad hay diversos ethos, diversos «temperamentos estimativos». Algunos de ellos «estiman las acciones difíciles y expuestas en que juega un papel lo más íntimo del hombre» ${ }^{87}$. No consideran su esfuerzo como una "mercancía», sino como «una parte de su propia persona que entregan libérrimamente»; por ejemplo, estiman y «aman los ejercicios corporales por sí mismos, como manifestaciones del lujo vital». Hay aquí un sentimiento y temperamento estimativo, una predilección «aristocrática» por el esfuerzo disciplinado, como en el ethos deportivo ${ }^{88}$.

\section{LOS VALORES INMANENTES A LA VIDA}

«El descubrimiento de los valores inmanentes a la vida fue en Goethe y en Nietzsche (...) una intuición genial» ${ }^{89}$, que en la interpretación de Ortega impulsó un viraje en el modo de sentir la existencia en favor del «sentido deportivo y festival de la vida». Sin embargo, Ortega señala que el "progresismo cultural» de los últimos siglos ha valorado más el esfuerzo en vista de sus resultados, es decir, el «esfuerzo obligado» del trabajo, que el «esfuerzo lujoso» del deporte. Ahora bien, a las obras más valiosas sólo se llega por medio de un esfuerzo «antieconómico», como ocurre en la creación científica y artística, el heroísmo moral, la santidad religiosa, que son para Ortega y Gasset «sublimes resultados del deporte $»^{90}$. Pues, más allá de la idolatría (la divinización) del trabajo y la política ha aparecido un nuevo valor en la cultura ${ }^{91}$ : «lo vital».

El nuevo valor de lo vital incorpora la «capacidad de sufrimiento» ${ }^{92}$. Esta «aceptación de lo doloroso es el fenómeno más admirable que existe en el universo». Por ejemplo, ocurre en el amor, "tanto amamos cuanto estamos dispuestos a sufrir por lo amado». Lo que hace Ortega es extender esta valoración del sufrimiento a todos los fenómenos más valiosos de la vida: «Todo lo excelente ha nacido de un lujo cordial», por el que se han producido «florecimientos» como la ciencia, el arte y el deporte, asumiendo «alegremente» los correspondientes «dolores». «Hay, pues, un mal dolor y un buen dolor». El

$87 \quad$ Ibid., 756.

88 Ortega y Gasset, J., O.C., "[Las reacciones utilitarias]» (1920), VII, 749-750.

89 Ortega y Gasset, J., O.C., «El tema de nuestro tiempo» (1923), III, 606-610.

$90 \quad$ Ibid., 609.

91 Sobre los valores intrínsecos del deporte y su potencial educativo insiste José Mario Hernández, «Apuntes sobre el discurso deportivo de Ortega y Gasset», Revista Española de Educación Física y Deporte, $\mathrm{n}^{\circ}$ 4, enero-junio, 2006, 121-136.

92 Ortega y Gasset, J., O.C., «Sobre el buen dolor» (1920), VII, 758-760 
mal dolor es «el que soportamos» y el buen dolor es «el que creamos». «El malo es el dolor sin sentido». El buen dolor es aquel en el que cabe descubrir «la gracia del dolor» y, en vez de ir contra la vida, constituye un «acicate vital». Y Ortega alude a tres cosas que «simbolizan el afán gigantesco de vivir»: el deporte, el heroísmo y el amor. El deporte es una de esas ocupaciones que manifiestan una sana «voluntad de dolor» y en que se sienten (viven) «penas fecundas $»^{93}$. El deporte ha sido desde antiguo una "ocupación aristocrática», que lleva incorporada la capacidad de sufrimiento fecundo ${ }^{94}$.

El cultivo de los deportes de «nuestro tiempo» ha sido impulsado por el "entusiasmo por el cuerpo», que es un hecho en el que queda patente el «triunfo de la juventud» y revela «el trastorno de valores en Europa $»^{95}$. En esta «era del culto al cuerpo» crece el "frenesí expansivo del deporte por todo el mundo ${ }^{96}$. Ortega observa el hecho del creciente avance de las informaciones deportivas con detrimento de otros temas «de sólito llamados serios» y llama la atención sobre lo que, a su juicio, significa: «el nuevo entusiasmo por el cuerpo, el triunfo de la corporeidad», una de cuyas principales manifestaciones es «la expansión torrencial de los deportes físicos» ${ }^{97}$.

Este cambio axiológico producido por la «nueva fe en el cuerpo» impregna la vida entera de las personas y configura su estilo vital. Ortega aprovecha este asunto del entusiasmo por el cuerpo y la creciente relevancia de los deportes para destacar la «nueva perspectiva» que necesitamos aprender para comprender la vida humana: que "para la vida todo es importante» (hasta lo ínfimo) y no sólo lo que le parece a su razón que lo es. La nueva atención al cuerpo descubre que «el cuerpo vivo no es un mineral sino carne, y que la carne a diferencia del mineral no es nunca sólo materia sino lugar donde habita el alma». La carne encierra «intimidad secreta y material», que «desde dentro modela un cuerpo»; por eso, «cuando vemos carne prevemos algo más que lo que vemos y algo que está en ella infuso, a la vez oculto tras ella y expresándose en ella. La carne es siempre gesto, tiene siempre sentido, significa un secreto. La carne es jeroglífico» ${ }^{98}$. Y desde él se fragua el sentido deportivo de la vida humana.

93 Ibid., 759.

94 Para la relación entre lo que significa ser aristocrático y el sufrimiento, vid., por ejemplo, F. Nietzsche, Más allá del bien y del mal, Alianza, Madrid, 1978, sección 9a .

95 Ortega y Gasset, J., O.C., «Meditación de nuestro tiempo. Introducción al presente» (1928), VIII, 63 y ss.

96 Ortega y Gasset, J., O.C., «¿Qué pasa en el mundo?»(1933), IX, 12 y 18.

97 Ortega y Gasset, J., O.C., «Meditación de nuestro tiempo. Introducción al presente» (1928), VIII, 65.

98 Ibid., 66-67. 


\section{BiBLIOGRAFÍA}

Apel, K.-O. (1976). Transformation der Philosophie. Frankfurt am Main: Suhrkamp.

Campioni, G. (2014). "Gaya ciencia" and "gay saber" en la filosofía de Nietzsche», en Conill-Sancho, J. y Sánchez-Meca, D. (eds.). Guía Comares de Nietzsche. Granada: Comares, pp. 71-91.

Cerezo, P. (1984). La voluntad de aventura. Barcelona: Ariel.

Conill, J. (1997). El poder de la mentira: Nietzsche y la política de la transvaloración. Madrid: Tecnos.

—, (2006). Ética hermenéutica: crítica desde la facticidad. Madrid: Tecnos.

Cortina, A. (2001). Alianza y contrato. Política, Ética y Religión. Madrid: Trotta.

Gadamer, H.-G. (1974). «Hermeneutik», en Ritter, J., Historisches Wörterbuch der Philosophie. Basel/Stuttgart: Schwabe, pp. 1061-1073.

Graham, J. T. (1994). A pragmatist philosophy of life in Ortega y Gasset. Columbia, SC: University of Missouri Press.

Hernández Pérez, J. M. (2006). «Apuntes sobre el discurso deportivo de Ortega y Gasset», Revista Española de Educación Física y Deporte, 4, pp. 121-36.

Huizinga, J. (1958). Homo ludens: vom Urspung der Kultur im Spiel. Hamburg: Rowohlt. Ilundáin-Agurruza, J. 2014. José Ortega y Gasset: Exuberant Steed. Sport, Ethics and Philosophy 8 (3), pp. 285-314.

Inglis, D. (2004). «Meditations on sport: On the trail of Ortega y Gasset's philosophy of sportive existence», Journal of the Philosophy of Sport, 31 (1), pp. 78-96.

Isidori, E., López, F. J. Frías, and Müller, A. (2014). Philosophy, sport and education: International perspectives. Viterbo: Sette Cittá.

Isidori, E. y Reid, H.L. (2011). Filosofia dello sport. Milan: B. Mondadori.

Lenk, H. (1982). «Tasks of the philosophy of sport: Between publicity and anthropology», Journal of the Philosophy of Sport, 9 (1), pp. 94-106.

López Frias, F. J. (2014). La filosofia del deporte actual. Paradigmas y corrientes principales. Rome: Quapeg.

Marcuse, H. (1970). Ontología de Hegel y teoría de la historicidad. Barcelona: Martinez Roca.

Morón Arroyo, C. (1968). El sistema de Ortega y Gasset. Madrid: Ediciones Alcalá.

Nietzsche, F. (1984). Así habló Zaratustra. Madrid: Alianza.

—, (1978). Más allá del bien y del mal. Madrid: Alianza.

Orringer, N. R. (1985). "Ortega, psicólogo y la superación de sus maestros», Azafea, 1 (1985), pp. 185-236.

Ortega y Gasset, J. (2004-2010). Obras Completas. 10 volúmenes (I-X). Madrid: Taurus.

—, (2004). El origen deportivo del estado, en Obras Completas, vol. II. Madrid: Taurus, pp. 705-719.

—, (2004). El Quijote en la escuela (1920), en Obras Completas, vol. II. Madrid: Taurus, pp. 401-430.

—, (2004). Ideas sobre Pio Baroja, en Obras Completas, vol. II, Madrid: Taurus, pp. 211241.

—, (2004). Las dos grandes metáforas (1924), en Obras Completas, vol. II. Madrid: Taurus, pp. 505-517.

-, (2004). No ser un hombre ejemplar (1924), en Obras Completas, vol. II. Madrid: Taurus, pp. 475-479.

—, (2004). Notas del vago estío (1925), en Obras Completas, vol. II. Madrid: Taurus, pp. 531-565. 
—, (2004). Sobre la expresión fenómeno cósmico (1925), en Obras Completas, vol. II. Madrid: Taurus, pp. 680-695.

—, (2004). Vitalidad, alma, espíritu (1924), en Obras Completas, vol. II. Madrid: Taurus, pp. 566-592.

—, (2005). Charla, nada más (1927), en Obras Completas, vol. IV, Madrid: Taurus, pp. 75-79.

—, (2005). El tema de nuestro tiempo (1923), en Obras Completas, vol. III. Madrid: Taurus, pp. 559-652.

—, (2005). Temple para la reforma, en Obras Completas, vol. IV, Madrid: Taurus, pp. 1034-1041.

—, (2006). Historia como sistema (1941), en Obras Completas, vol. VI. Madrid: Taurus, pp. 45-81.

—, (2006). Prólogo a Veinte años de caza mayor, del Conde de Yebes (1943), en Obras Completas, vol. VI. Madrid: Taurus, pp. 269-333.

—, (2007). El sentido deportivo de la vitalidad (1924), en Obras Completas, vol. VII. Madrid: Taurus, pp. 818-834.

—, (2007). Las reacciones utilitarias (1920), en Obras Completas, vol. VII. Madrid: Taurus, pp. 749-750.

—, (2007). Militares y clases mercantiles (1920), en Obras Completas, vol. VII. Madrid: Taurus, pp. 754-757.

—, (2008). ¿Qué es la ciencia, qué es la filosofía? (1928), en Obras Completas, vol. VIII. Madrid: Taurus, pp. 117-170.

—, (2007). Sobre el buen dolor (1920), en Obras Completas, vol. VII. Madrid: Taurus, pp. $758-760$.

—, (2008). Meditación de nuestro tiempo. Introducción al presente (1928), en Obras Completas, vol. VIII. Madrid: Taurus, pp. 31-114.

—, (2008). ¿Qué es la filosofía? (1929), en Obras Completas, vol. VIII. Madrid: Taurus, pp. 235-374.

—, (2009). La idea de principio en Leibniz (1947), en Obras Completas, vol. IX. Madrid: Taurus, pp. 929-1174.

—, (2009). La razón histórica (1940), en Obras Completas, vol. IX, Madrid: Taurus, pp. 477-558.

—, (2009). La razón histórica (1944), en Obras Completas, vol. IX, Madrid: Taurus, pp. 625-700.

—, (2009). ¿Qué pasa en el mundo? (1930), en Obras Completas, vol. IX. Madrid: Taurus, pp. 9-26.

—, (2010). El hombre y la gente, en Obras Completas, vol. X. Madrid: Taurus, pp. 137326.

Regalado, A. (1990). El laberinto de la razón: Ortega y Heidegger. Madrid: Alianza.

Suits, B. (2005). «Construction of a definition», en The Ethics of sports. A reader, edited by M. McNamee. London: Routledge, pp. 17-28.

Tuncel, Y. (20013). Agon in Nietzsche. Milwaukee, WI: Marquette University Press.

Zamora Bonilla, J. (2002). Ortega y Gasset. Barcelona: Plaza \& Janés.

[Artículo aprobado para publicación e enero de 2019] 